\title{
O ANTEPROJETO DA CVM PARA A REFORMA DA LEI DE SOCIEDADES POR AÇÕES BRASILEIRA
}

\author{
Waldirio Bulgarelli \\ Professor Titular do Departamento de Direito Comercial \\ da Faculdade de Direito da Universidade de São Paulo
}

\begin{abstract}
Resumo:
O presente artigo põe em evidência aspectos da reforma da lei das companhias brasileiras. Trata-se do Anteprojeto de lei apresentado à audiência pública pela Comissão de Valores Mobiliários (CVM), órgão federal de controle e fiscalização das companhias, criado no Brasil nos moldes da SEC (Security Exchange Commission) norte-americana.

Procura-se adaptar com ele, a Lei n. 6.404, de dezembro de 1976, às novas realidades do país, após cerca de quinze anos de vigência.

O texto do artigo é assim marcantemente informativo, objetivando dar conhecimento da reforma que se pretende.
\end{abstract}

\begin{abstract}
:
This present article refers to relevants aspects in relation to the law's reform of the brazilian's corporations. It concerns the Anti-project of the law presented to the public audience by the CVM, Comissão de Valores Mobiliários, a federal department that controls and supervises the companies, created in Brazil on the basis of the north-american SEC, Security Exchange Commission.

The purpose is to adapt Law \# 6.404, dated december 1976 and current for fifteen years, to the new realities of the country, through the aforementioned Anti-project.

The text of the article is, thus, strikingly informative, purposefully advertising the intended reform.
\end{abstract}

1. A divulgação do Anteprojeto de reforma da Lei n. 6.404/76, elaborado e divulgado pela Comissão de Valores Mobiliários, para através de audiência pública receber sugestões, justifica uma análise do texto oferecido, ainda que resumida.

2. A respeito do tema, dois aspectos devem ser salientados: $a$. que a Exposição de Motivos da atual Lei enfatizou o seu caráter experimental, talvez motivada pelos calorosos debates que o então Anteprojeto ensejou e, em virtude do número e profundidade das inovações que propunha e que de fato introduziu 
no plano da Lei das Sociedades por Ações, o então vigente Decreto-lei n. 2.627, de $1940 ;$ b. que, certamente, não seria fácil a absorção pelo meio jurídico e empresarial de transformações tão profundas numa lei que já se enraizara na consciência, nos costumes e na práxis, eis que vigeu para mais de trinta anos. Por tal aspecto, as manifestações ocorridas pelo décimo aniversário da Lei, em 1986, ressaltaram suas qualidades e cito nominalmente o artigo do professor Arnoldo Wald, publicado na $R D M$ n. 62 (1986), que entoava loas aos dispositivos da Lei em exame, e outras no mesmo tom, o que indicava que grande parte das inovações já haviam sido compreendidas. Nem todas, é verdade, e nesse sentido os pleitos judiciais coletados dão bem um exemplo das dificuldades que os Tribunais encontraram para dar desate correto aos dissídios provocados, em que avultam os referentes aos choques entre maioria e minoria, os concernentes a uma incompreensão até conceitual da figura do controlador, os referentes ao Conselho Fiscal e assim por diante. Bem é de ver que a Lei n. 6.404/76, a par do grande número de dispositivos contidos nos seus trezentos artigos, somados aos quinze que manteve em vigor da Lei anterior e às remissões diretas ou indiretas a outras leis, já constituía por si um complicador para o seu entendimento sistemático, ao que se acresciam os vários tipos, digamos assim, de sociedades por ações por ela disciplinados, como: o regime das companhias abertas e das fechadas, sem uma separação nítida no tratamento, tendo se chegado após minucioso estudo, a assinalar pelo menos vinte e uma série de disposições específicas; das sociedades de capital autorizado, das sociedades em comandita por ações, das sociedades de economia mista, dos grupos de fato e de direito, dos consórcios, e ainda dos reflexos nas sociedades por cotas de responsabilidade limitada, sobretudo, em termos de transformação, incorporação, fusão e cisão. Tudo isto somado explica a extensa bibliografia surgida para analisar seus dispositivos, como muitas obras, diga-se de ocasião, e outras mais pensadas, e também o incontável número de pareceres que ainda hoje são oferecidos em relação aos temas tratados. Deve-se ressaltar que um dos temas que mais causou impressão foi o da proteção às minorias, o que chamou inclusive minha atenção, pois envolvia toda a sistemática das companhias, alcançando o controlador e suas responsabilidades, assim como os administradores, a distribuição dos dividendos, a questão das reservas, as formalidades das assembléias gerais, a aprovação de contas de administradores, a divisão das ações em formas e espécies, e ainda o 
Conselho Fiscal, tendo de mim, se me permitem a referência, merecido pelo menos duas monografias específicas, uma intitulada $A$ proteção às minorias na sociedade anônima, e outra, que foi tese de concurso com o qual obtive a titularidade da cadeira de direito comercial da Faculdade de Direito da USP, justamente sobre o tema do Conselho Fiscal.

3. Passando à análise do Anteprojeto oferecido agora pela CVM, dois aspectos significantes despertam desde logo a atenção: 1. que optou a CVM por introduzir alterações, sem quebrar a seqüência da Lei, ao contrário do que está ocorrendo com a pretendida reforma da Lei de Falências e Concordatas, em que se optou pelo oferecimento de um novo texto; 2. que as inovações introduzidas visam, pela perspectiva técnica, a aprimorar o funcionamento do modelo, como se vê, por exemplo, em relação às demonstrações contábeis que vieram substituir as antigas demonstrações financeiras, além de critérios de avaliação dos ativos e passivos, e da criação de um conselho para orientar a contabilidade, o COSENC, composto de membros de várias entidades (art. 302); e de outro, aprimorar o sistema de proteção às minorias, e ainda por esse aspecto, dando maior realce às preferências, como que pretendendo que se tornem algo mais do que meras ações de segunda classe, como já foram consideradas pela doutrina. Ainda nessa linha faz referência a empresas de grande porte, o que é altamente sugestivo (cf. art. 301).

4. Será, portanto, seguindo essa linha que iremos destacar algumas das principais alterações, sem qualquer pretensão exaustiva.

Comecemos pelas ações preferenciais.

Alterou-se a proporcionalidade no capital, fixando-se em $40 \%$ (e não mais $2 / 3$ do capital) do total das ações emitidas, conforme o texto do art. 15 , $\S 2^{\circ}$, que convém transcrever:

"O número de açōes preferenciais sem direito a voto, ou sujeitas a restrições no exercício desse direito, não pode ultrapassar a quarenta por cento (40\%) do total das açōes emitidas".

Já no que tange às preferências, fixou-as o art. 17, como prioridade: I - na distribuição de dividendos; II - no reembolso do capital com ou sem 
prêmio; e III - no resgate, na amortização ou no reembolso. Quanto ao voto, manteve-se a sistemática, inserindo $o$ art. 18 a disposição de que elas poderão ter voto pleno, restrito ou não possuírem direito a voto, conforme disponha o estatuto social. Cabe mencionar a propósito dois pontos salientes: um, referente à inclusão entre os direitos essenciais do art. 109, do inciso VI, "exercer o direito de voto de acordo com esta Lei"; o outro, o de que as açôes preferenciais de voto restrito votam em igualdade de condições com as ações ordinárias, além de outras situações previstas nos estatutos sociais, para: "I - eleger ou demitir, total ou parcialmente, o Conselho Fiscal; II - escolher ou demitir se houver os auditores independentes; III - deliberar sobre o aumento do capital social com emissão de açōes preferenciais; $I V$ - decidir sobre o aumento do capital social mediante a integralização em bens e créditos; $V$ - alterar a política de dividendos estabelecida no estatuto social; $V I$ - emissão de debêntures conversíveis em açōes; VII - emissão de bônus de subscriçāo".

Chama a atenção, a alteração procedida através do art. 111, que dispõe:

"O estatuto poderá conferir às açōes preferenciais algum ou alguns dos direitos reconhecidos às açōes ordinárias além daqueles previstos nesta Lei.

$\S 1$ - As ações preferenciais sem direito a voto, $e$ as de voto restrito, serão transformadas em ações ordinárias votantes, por expressa manifestação do acionista, caso a companhia: a. deixar de distribuir, em até 120 dias (cento e vinte) do término do exercício social, o dividendo atribuído às açōes preferenciais sem direito a voto; $b$. após dois exercícios sociais, deixar de pagar os dividendos fixos cumulativos ou mínimos a que fizerem jus".

Nota-se, a propósito, que não se trata mais, agora, de simplesmente adquirir o exercício do direito de voto, mas da transformação da ação preferencial em ordinária, o que constitui um passo significativo na consagração da posição das preferenciais. 
Nesse sentido, vê-se também que foi revogado o atual disposto no art. 18 que permite ao estatuto assegurar a uma ou mais classes de ações preferenciais o direito de eleger, em votação em separado, um ou mais membros do Conselho de Administração (que constituía uma das formas de integração em joint venture); assim como o parágrafo único, que dispõe que o estatuto pode subordinar as alterações estatutárias que especificar à aprovação, em assembléia especial, dos titulares de uma ou mais classes de ações preferenciais, o que, em princípio, parece não retirar esse poder dos controladores.

Alcança também o esquema das preferenciais a remuneração dos administradores, tendo o art. 152 , no seu $\S 1$, estabelecido que o estatuto da companhia que fixar o dividendo obrigatório em $25 \%$ (vinte e cinco por cento) ou mais do lucro líquido para as ações com voto restrito e pleno bem como em 9\% (nove por cento) ou mais para as ações preferenciais sem direito a voto, pode atribuir aos administradores participação no lucro da companhia; e ainda, o $\S 2$, que passou a ter a seguinte redação:

"O montante das participações não ultrapassará a remuneração anual dos administradores atualizada monetariamente, na forma do art. 184, nem $40 \%$ (quarenta por cento) do montante dos dividendos prevalecendo o limite que for menor".

As alterações referentes às ações preferenciais vão alcançar também a sua participação nas sociedades de economia mista, tendo o art. 239 sido alterado para apresentar a seguinte redação:

"As companhias de economia mista terão obrigatoriamente Conselho de Administração, composto por, no mínimo, 6 (seis) conselheiros, assegurado à minoria dos acionistas preferenciais o direito de eleger 3 (três) conselheiros, se maior número nâo lhes couber pelo processo de voto múltiplo"

No que tange à Assembléia Geral, algumas alterações merecem relevo; assim, a possibilidade de que qualquer acionista possa pedir que a CVM se faça representar, na Assembléia, correndo por conta o custo (parágrafo único do 
art. 121). Nessa linha observa-se também que a ata da Assembléia deverá ser distribuída aos acionistas e que estes poderão por qualquer meio gravar o ocorrido na Assembléia (cf. art. 130 e $\$ 4^{9}$ ).

Quanto à convocação, alterou-se o quorum estabelecido na alínea $c$ do art. 123, para acionistas que representem $2 \%$ (dois por cento), no mínimo, do capital, quando os administradores não atenderem, no prazo de oito dias, o pedido de convocação que apresentarem devidamente fundamentado com indicação das matérias a serem tratadas.

Vale ainda mencionar que em relação à deliberação para contratar auditores independentes (o que não é mais obrigatório, como na atual Lei) pode ser invocado por acionistas que representem 0,1 décimo do capital social, o processo do voto múltiplo.

Aliás, a respeito do voto múltiplo, convém destacar que se alterou a sistemática. Assim, o art. 141 dispõe agora:

"Na eleição dos conselheiros, é facultado aos acionistas que representem, no mínimo, 0,1 (um décimo) das ações ordinárias com direito a voto, esteja ou não previsto no estatuto, requerer a adoção do processo de voto múltiplo, atribuindo-se a cada ação, tantos votos quantos sejam os membros do Conselho, $e$ reconhecido ao acionista o direito de cumular os votos num só candidato ou distribui-los entre vários",

ao que se acresce a alteração do § 4º, que dispõe:

"Se o número de membros do Conselho de Administração for inferior a 5 (cinco) é facultado aos acionistas que representem $20 \%$ (vinte por cento), no mínimo, do capital constituído por ações ordinárias com direito a voto, a eleição de um dos membros do Conselho, observado o disposto no $\$ 1^{Q^{\prime \prime}}$.

Na parte que se refere ao controlador, tem-se modificação no sentido de alcançar os empregados (art. 117, $d$ e $e$ ). 
Quanto aos administradores, acresceu-se suas obrigações, no art. $154, \S 2^{2}$, que se apresentam como vedações, ficando assim impedido o administrador de

"negar-se a prestar, oralmente ou por escrito, antes ou quando das assembléias gerais, qualquer informação, ou negar-se a mostrar ou fornecer cópia de qualquer documento que, direta ou indiretamente, esteja relacionado com as matérias constantes na ordem do dia ou na assembléia discutidos" (alínea $d$ )

e ainda

"deixar de comunicar aos acionistas, na primeira
assembléia, a existência de inquérito ou processo
administrativo iniciado pela administração pública
federal, estadual ou municipal contra a companhia ou
qualquer dos seus administradores" (alínea $e$ ).

Alterou-se também a figura do conflito de interesses, acrescendo-se um $\S 3^{\circ}$ e modificando-se o $\S 2^{\circ}$ que passou a ter a seguinte redação:

"Se o administrador, observado o disposto no $\S 1$, direta ou indiretamente, contratar com a companhia, deverá comunicar tal fato, por escrito e detalhadamente, na primeira assembléia geral que se realizar";

e rezando o $\S 3^{\circ}$ :

"O negócio contratado com infraçāo ao disposto nos parágrafos $1^{Q}$ e $2^{Q}$ é anulável, $e$ o administrador interessado será obrigado a transferir para a companhia as vantagens que dele tiver auferido".

As alterações procedidas no direito de recesso, além de ampliá-lo, também restauraram a redação original que foi alterada, como se sabe, pela chamada Lei Lobão (n. 7.958, de 20.12.1989), que provocou grandes debates, entendendo a maioria (cf. Mauro Rodrigues Penteado, $R D M$ n. 77/29 e Rubens 
Aprobato Machado, $R D M$ n. 82/46) que não havia revogado os arts. 225 a 230 da Lei n. 6.404/76. Como o art. 137 liga-se ao 136, verifica-se que este foi alterado com relação ao quorum para aprovação das matérias que especifica, passando para metade das ações com direito a voto e com voto restrito. Já no que tange ao art. 137 propriamente dito, passou a ter a seguinte redação:

"A aprovação das matérias previstas nos incisos I a VII do art. 136, desta Lei, dá ao acionista dissidente direito de retirar-se da companhia, mediante reembolso do valor de suas açóes (art. 45) se o reclamar à companhia, no prazo de 30 (trinta) dias contados da publicação da ata da assembléia geral.

$\S 1^{Q}$ - $O$ acionista dissidente da assembléia, inclusive o titular de ações preferenciais com direito a voto restrito ou sem direito a voto, pode pedir o reembolso do valor das ações de que, comprovadamente, era titular na data da assembléia, ainda que se tenha abstido de votar contra a deliberaçāo ou não tenha comparecido à reunião".

Vê-se, assim, que do rol das matérias previstas no art. 136, o Anteprojeto só retirou o direito de recesso para o inciso VIII, que se refere à constituição de grupo, mantendo-se esse direito em caso de fusão, incorporação ou cisão, de acordo com a nova redação dada ao art. 230.

Modificações interessantes foram introduzidas na configuração e atribuições do Conselho Fiscal, sendo que alguns ajustes atenderam a sugestões que fizemos em nossa tese sobre o tema (cf. O Conselho Fiscal nas companhias brasileiras, São Paulo, Revista dos Tribunais, 1988). Destarte verifica-se desde logo que se alterou a redação do caput do art. 163, passando as atribuições nele mencionadas a ser não do órgão mas dos conselheiros.

Por outro lado, passou o órgão a ser permanente nas companhias abertas. O que causa espécie, no entanto, é a composição do órgão, com o número entre 3 e 5 , o que parece não corresponder às contas dos componentes. Assim é que o Anteprojeto estatui que os titulares de ações sem direito a voto terão o direito de eleger, em votação em separado, um membro e respectivo 
suplente, tendo-se mantido a sistemática anterior "para os demais acionistas" que elegem um mais um; tudo somado resulta em três, não se vendo como poderá chegar a cinco.

Também introduziu alteraçóes no acordo de acionistas, que nos parecem, aliás, bem oportunas; assim é que além dos três objetos relacionados anteriormente no art. 118 introduziu-se "outras preferências", o que amplia bastante a incidência do acordo. Também fixou prazo máximo de 4 (quatro) anos para os acordos e outorgou o direito de renúncia aos seus participantes.

Algumas outras alterações merecem menção ainda que sumárias: assim, a sujeição das sociedades de economia mista à falência, o que se casa aliás com o Anteprojeto governamental de reforma da Lei de Falências e Concordatas que previu o mesmo. Também as sociedades por cotas de responsabilidade limitada e demais tipos de sociedades, desde que de grande porte, ficam sujeitas à elaboração de demonstrações financeiras de acordo com a Lei e as normas da CVM.

Para requerer a adoção do voto múltiplo, foi alterada a porcentagem anterior do art. 141, passando agora para um mínimo de 0,1 (um décimo) das ações ordinárias com direito a voto; assim também a porcentagem do $\S 4^{Q}$ passou a ser computada sobre o capital constituído por ações ordinárias com direito a voto.

Um sem-número de outras alterações foram sugeridas, mas elencálas todas seria ampliar demais o presente trabalho que tem como escopo apenas sinalizar para as mais chamativas. 